\title{
Hydrothermal synthesis and electrochemical properties of a coordination polymer based on dinuclear (Pyrazinyl tetrazolate) Copper(II) cations and $\beta$-Octamolybdate Anions
}

\author{
SHAOBIN LI ${ }^{\mathrm{a}, \mathrm{b}}$, LI ZHANG $^{\mathrm{a}}$, HUIYUAN MA ${ }^{\mathrm{a}, *}$ and HAIJUN PANG ${ }^{\mathrm{a}, *}$ \\ ${ }^{a}$ Key Laboratory of Green Chemical Engineering and Technology, College of Heilongiiang \\ Province, College of Chemical and Environmental Engineering, Harbin, \\ University of Science and Technology, Harbin 150040 China \\ ${ }^{\mathrm{b}}$ College of Materials Science and Engineering, Qiqihar University, Qiqihar 161006, China \\ e-mail: mahy017@163.com; panghj116@163.com
}

MS received 29 October 2015; revised 20 January 2016; accepted 14 March 2016

\begin{abstract}
A hybrid compound $\left(\mathrm{H}_{2}\right.$ bbi) $\left[\mathrm{Cu}_{2}(\text { pzta })_{2}\left(\mathrm{H}_{2} \mathrm{O}\right)_{2}\right]\left[\beta-\mathrm{Mo}_{8} \mathrm{O}_{26}\right](\mathbf{1})$ (pztaH $=5$-(2-pyrazinyl) tetrazolate, bbi $=1,1^{\prime}-(1,4$-butanediyl)bis(imidazole), has been hydrothermally synthesized and characterized by elemental analysis, IR spectroscopy and single-crystal X-ray diffraction. In $\mathbf{1}$, the $\beta$-Mos clusters link dinuclear copper (II) complexes as bidentate connectors to form inorganic-organic chains. These chains and the $\left[\mathrm{H}_{2} \mathrm{bbi}\right]^{2+}$ counter-cations are fused together forming layers via hydrogen bonding interactions. The electrochemical properties of $\mathbf{1}$ were studied. The results indicate that $\mathbf{1}$ has an electrocatalytic activity towards the reduction of iodate ascribed to the Mo-centers.
\end{abstract}

Keywords. Polyoxometalates; octamolybdate; dinuclear copper complexes; electrochemical properties.

\section{Introduction}

Polyoxometalates (POMs) are comprised of earlytransition metals with $\mathrm{d}^{0}$ or $\mathrm{d}^{1}$ electronic configurations (usually $\mathrm{Mo}^{\mathrm{VI}}, \mathrm{W}^{\mathrm{VI}}, \mathrm{V}^{\mathrm{V}}, \mathrm{Nb}^{\mathrm{V}}$ or $\mathrm{Ta}^{\mathrm{V}}$ ), which have attracted intense attention during the last two decades not only for their remarkable structural and electronic properties, but also for their potential applications in catalysis, electrochemistry and medicine. ${ }^{1-6}$ Coordination polymers are a new generation of solidstate materials that have promising applications in gas storage, catalysis, and porous materials due to their unique structural and functional properties. ${ }^{7-9}$ In virtue of their special properties, it is appealing to construct POM-based coordination polymers, which may combine the advantages of both POMs and coordination polymer, and thus many novel POM-based coordination polymers have been obtained in recent years. ${ }^{10-13}$ Among various POM-based coordination polymers, the coordination polymers based on POMs and dinuclear copper(II) complexes have gained the attention of chemists. Since the first example of coordination polymer based on POMs and dinuclear copper(II) complexes reported by Gutiérrez-Zorrilla and coworkers in $2003,{ }^{14}$ some of this kind of hybrids have been

\footnotetext{
*For correspondence
}

successfully synthesized. ${ }^{15-18}$ However, to date, such hybrids reported in literature are limited in number. Therefore, the extended studies in this branch are still very significant.

To construct POM-based dinuclear copper(II) compounds, the choice of ligands is vital. The multidentate rigid ligand 5-(2-pyrazinyl) tetrazole (pztaH) possesses flexible coordination modes (scheme 1) due to their six potential nitrogen coordination sites, namely the adjacent four nitrogen atoms of tetrazolyl and the two nitrogen atoms of pyrazinyl, and thus the pzta is readily available to coordinate metal ions for affording polynuclear metal clusters. In our previous work, four POM-based dinuclear/tetranuclear copper(II) compounds constructed by the multidentate pztaH ligand have been synthesized. ${ }^{19,20}$ Moreover, the flexibile bbi ligand (scheme 1) as a secondary N-donor ligand, with two terminal nitrogen atoms in imidazole rings and good coordination ability to coordinate metal ions, is easily protonated and thus bbi possesses potential sites for hydrogen bonding towards oxygen atoms of POMs and/or water molecules forming $\mathrm{N}-\mathrm{H}$... O interactions. Such interactions together with coordination ability of the terminal nitrogen atoms in imidazole rings can effectively extend the structures. Meanwhile, the two imidazole rings can twist freely around the $-\mathrm{CH}_{2}$ - group 


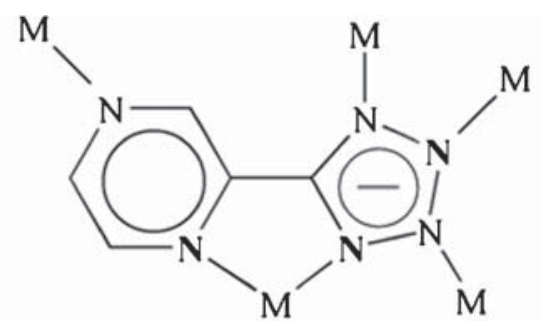

pzta

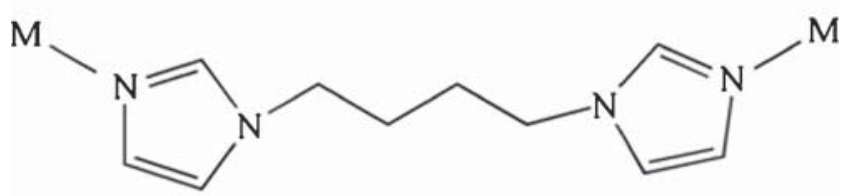

bbi

Scheme 1. View of the potential coordination sites of pzta and bbi ligands.

to meet the requirements of the coordination geometries in the assembly process.

As an extension of our previous work, among the various types of POMs, the octamolybdates $\left(\mathrm{Mo}_{8}\right)$ have attracted much attention because of their high reactivities and diverse isomers. In this context, we chose the combination of the multidentate ligand pztaH and the flexible bbi ligand to construct POM-based coordination polymer. A new compound $\left(\mathrm{H}_{2}\right.$ bbi) $\left[\mathrm{Cu}_{2}(\text { pzta })_{2}\right.$ $\left.\left(\mathrm{H}_{2} \mathrm{O}\right)_{2}\right]\left[\beta-\mathrm{Mo}_{8} \mathrm{O}_{26}\right]$ (1) has been successfully synthesized under hydrothermal conditions. In addition, the electrocatalytic properties of $\mathbf{1}$ were investigated.

\section{Experimental}

\subsection{Materials and methods}

All the chemicals were of reagent grade and used without further purification. Elemental analyses $(\mathrm{C}, \mathrm{H}$ and $\mathrm{N})$ were performed on a Perkin-Elmer $2400 \mathrm{CHN}$ Elemental Analyzer. The FT-IR spectra were recorded from $\mathrm{KBr}$ pellets in the range $4000-400 \mathrm{~cm}^{-1}$ with a Nicolet AVATAR FT-IR360 spectrometer. A CHI660 electrochemical workstation was used for control of the electrochemical measurements and data collection. A conventional three-electrode system was used, with a carbon paste electrode (CPE) as a working electrode, commercial $\mathrm{Ag} / \mathrm{AgCl}$ as reference electrode and a twisted platinum wire as counter electrode.

\subsection{Synthesis of compound 1}

A mixture of $\left(\mathrm{NH}_{4}\right)_{6} \mathrm{Mo}_{7} \mathrm{O}_{24} \cdot 4 \mathrm{H}_{2} \mathrm{O}(0.37 \mathrm{~g}, 0.3 \mathrm{mmol})$, $\mathrm{CuCl}_{2} \cdot 2 \mathrm{H}_{2} \mathrm{O}(0.16 \mathrm{~g}, 0.9 \mathrm{mmol})$, pzta $(0.059 \mathrm{~g}, 0.4$ mmol), bbi (0.076 g, $0.4 \mathrm{mmol})$, and $\mathrm{H}_{2} \mathrm{O}(15 \mathrm{~mL})$ were stirred for $1 \mathrm{~h}$. Then the solution was sealed in a 23 $\mathrm{mL}$ Teflon-lined autoclave and heated at $170^{\circ} \mathrm{C}$ for 3 days with a starting $\mathrm{pH}=3.5$ adjusted by $1 \mathrm{M} \mathrm{HCl}$. After slow cooling to room temperature, blue blockshaped crystals of 1 were filtered, washed with distilled water and dried at room temperature $(46 \%$ yield based on Mo).The final $\mathrm{pH}$ value of the solution after the reaction was approximated to 3.2. Elemental analysis for $\mathrm{C}_{20} \mathrm{H}_{26} \mathrm{Cu}_{2} \mathrm{Mo}_{8} \mathrm{~N}_{16} \mathrm{O}_{28}$ (1) (1833.14): H, 1.43; C, 13.10; N, 12.23; Cu, 6.93; Mo, 41.87\%. Found: H, 1.35; C, 13.19; N, 12.31; Cu, 6.84; Mo, 41.79\%.

\subsection{X-Ray Crystallographic Study}

A single crystal of $\mathbf{1}$ was carefully selected for X-ray diffraction analysis. Data collection were performed on a Rigaku RAXIS-RAPID instrument equipped with a narrow-focus, $5.4 \mathrm{~kW}$ sealed tube X-ray source (graphit e-monochromated $\mathrm{Mo} K \alpha$ radiation $\lambda=0.71073 \AA$ ). The data were collected at a temperature of $293 \mathrm{~K}$. The data were processed with the PROCESS-AUTO program. The structure of $\mathbf{1}$ was solved by Direct Methods

Table 1. Crystal data and structure refinement data for $\mathbf{1}$.

\begin{tabular}{|c|c|}
\hline Empirical formula & $\mathrm{C}_{20} \mathrm{H}_{26} \mathrm{Cu}_{2} \mathrm{Mo}_{8} \mathrm{~N}_{16} \mathrm{O}_{28}$ \\
\hline$M r$ & 1833.14 \\
\hline Color, habit & blue, block \\
\hline Crystal size, $\mathrm{mm}^{3}$ & $0.36 \times 0.32 \times 0.28$ \\
\hline Crystal system; space group & triclinic; $P \overline{1}$ \\
\hline$a \AA$ & $9.7012(7)$ \\
\hline$b \AA$ & $11.1792(8)$ \\
\hline$c \AA$ & $11.2056(8)$ \\
\hline$\alpha, \operatorname{deg}$ & $118.447(1)$ \\
\hline$\beta$, deg & $95.778(1)$ \\
\hline$\gamma, \operatorname{deg}$ & $93.443(1)$ \\
\hline$V, \AA^{3}$ & $1054.97(13)$ \\
\hline$Z$ & 1 \\
\hline$D_{\text {calcd }} \cdot \mathrm{g} \mathrm{cm}^{-3}$ & 2.88 \\
\hline$\mu(\operatorname{Mo} K \alpha), \mathrm{mm}^{-1}$ & 33.9 \\
\hline$F(000) . \mathrm{e}$ & 870.0 \\
\hline$h k l$ range & $\begin{array}{l}-12 \leq h \leq 12 \\
-14 \leq k \leq 13 \\
-10 \leq l \leq 14\end{array}$ \\
\hline Absorption correction & multi-scan \\
\hline Refl. measured/unique & $6576 / 5211$ \\
\hline$R_{\text {int }}$ & 0.0125 \\
\hline Data/parameters & 4816 / 334 \\
\hline $\operatorname{GoF}\left(F^{2}\right)$ & 1.078 \\
\hline$R_{1} / w R_{2}[I>2 \sigma(I)]^{\mathrm{a}, \mathrm{b}}$ & $0.0269 / 0.0725$ \\
\hline$R_{1} / w R_{2}$ (all data) & $0.0293 / 0.0738$ \\
\hline$\Delta \rho_{\text {fin }}(\max / \min )$, e $\AA^{-3}$ & $0.78 /-0.16$ \\
\hline
\end{tabular}


and refined by full-matrix least-squares on $F^{2}$ using the SHELXTL-97 crystallographic software package. ${ }^{21}$ Anisotropic displacement parameters were used to refine all non-hydrogen atoms. The organic hydrogen atoms were generated geometrically. The hydrogen atoms of the water molecule in $\mathbf{1}$ could not be introduced in the refinement but were included in the structure factor calculation. Further details of the X-ray structure analysis are given in table 1 . Selected bond lengths and angles are listed in table S1 (in Supplementary Information). Crystal data and structure refinement, bond lengths and angles, and anisotropic displacement parameters have been deposited.

\section{Results and Discussion}

It is worth noting that $\mathrm{Mo}_{8}$ could be easily formed in situ by using $\left(\mathrm{NH}_{4}\right)_{6} \mathrm{Mo}_{7} \mathrm{O}_{24} \cdot 4 \mathrm{H}_{2} \mathrm{O}$ precursor under acid medium. ${ }^{22-25}$ We deduce the conversion pathways of the $\left[\mathrm{Mo}_{7} \mathrm{O}_{24}\right]^{6-}$ anion into the $\left[\beta-\mathrm{Mo}_{8} \mathrm{O}_{26}\right]^{4-}$ anion according to the following acid-base equilibrium (eq. 1):

$$
8\left[\mathrm{Mo}_{7} \mathrm{O}_{24}\right]^{6-}+20^{\mathrm{H}+} \rightarrow 7\left[\beta-\mathrm{Mo}_{8} \mathrm{O}_{26}\right]^{4}+10 \mathrm{H}_{2} \mathrm{O}
$$

\subsection{Description of the Crystal Structure}

The single-crystal X-ray diffraction analysis has shown that 1 consists of one $\beta$-[ $\left[\mathrm{Mo}_{8} \mathrm{O}_{26}\right]^{4-}$ anion (abbreviated as $\beta-\mathrm{Mo}_{8}$ ), two $\mathrm{Cu}$ cations, two pzta ligands, one biprotonated bbi ligand and two water molecules (figure 1). The Mo atoms are in +6 oxidation state and the $\mathrm{Cu}$ atoms in +2 oxidation state, confirmed by their BVS calculations, ${ }^{26}$ the coordination environments and green crystal color.

There are three basic subunits in 1: a dinuclear copper cation $\left[\mathrm{Cu}_{2}(\text { pzta) })_{2}\left(\mathrm{H}_{2} \mathrm{O}\right)_{2}\right]^{2+}(\mathbf{I})$, a $\beta-\mathrm{Mo}_{8}$ anion (II) and a biprotonated GTG conformation $\left[\mathrm{H}_{2} \mathrm{bbi}\right]^{2+}$ cation (III) $(\mathrm{G}=$ gauche, $\mathrm{T}=$ trans) (figure 2$)$. In subunit $\mathrm{I}$, there is one crystallographically unique $\mathrm{Cu}$ cation, and showing a five-coordination in a rectangular pyramidal geometry achieved by three $\mathrm{N}$ atoms from two pzta ligands, as well as two $\mathrm{O}$ atoms from a $\beta-\mathrm{Mo}_{8}$ cluster and one coordinated water molecule. The bond lengths and angles around the $\mathrm{Cu}$ ions are in the ranges of $1.965(3)-2.038(3) \AA(\mathrm{Cu}-\mathrm{N}), 1.958(3)-2.315(2)$ $\AA(\mathrm{Cu}-\mathrm{O}), 94.27(11)-172.00(11)^{\circ}(\mathrm{N}-\mathrm{Cu}-\mathrm{N})$, and $89.37(10)-171.96(12)^{\circ}(\mathrm{N}-\mathrm{Cu}-\mathrm{O})$. All of these bond lengths and bond angles are within the normal ranges observed in other $\mathrm{Cu}$ (II)-containing complexes. ${ }^{27}$ By these coordination modes, a dinuclear copper(II) complex is formed (figure 2a), in which the distance of two copper atoms $\left(\mathrm{Cu} 1 \cdots \mathrm{Cu} 1^{1 \#}\right)$ is $4.009 \AA$.

The dinuclear copper(II) complex shares its connecting nodes with neighboring $\beta-\mathrm{Mo}_{8}$ clusters giving rise to an inorganic-organic chain. The inorganicorganic chains and the $\left[\mathrm{H}_{2} \text { bbi }\right]^{2+}$ counter-cations are fused together to form layers with windows $c a$. $11.179 \times 16.131 \AA$ via hydrogen bonding interactions $(\mathrm{C} 10-\mathrm{H} 10 \cdots \mathrm{O} 4=3.28 \AA, \mathrm{C} 9-\mathrm{H} 9 \cdots \mathrm{O} 8=3.36 \AA)$ (figures $2 \mathrm{c}$ and $2 \mathrm{~d}$ ). From a topological view, if each

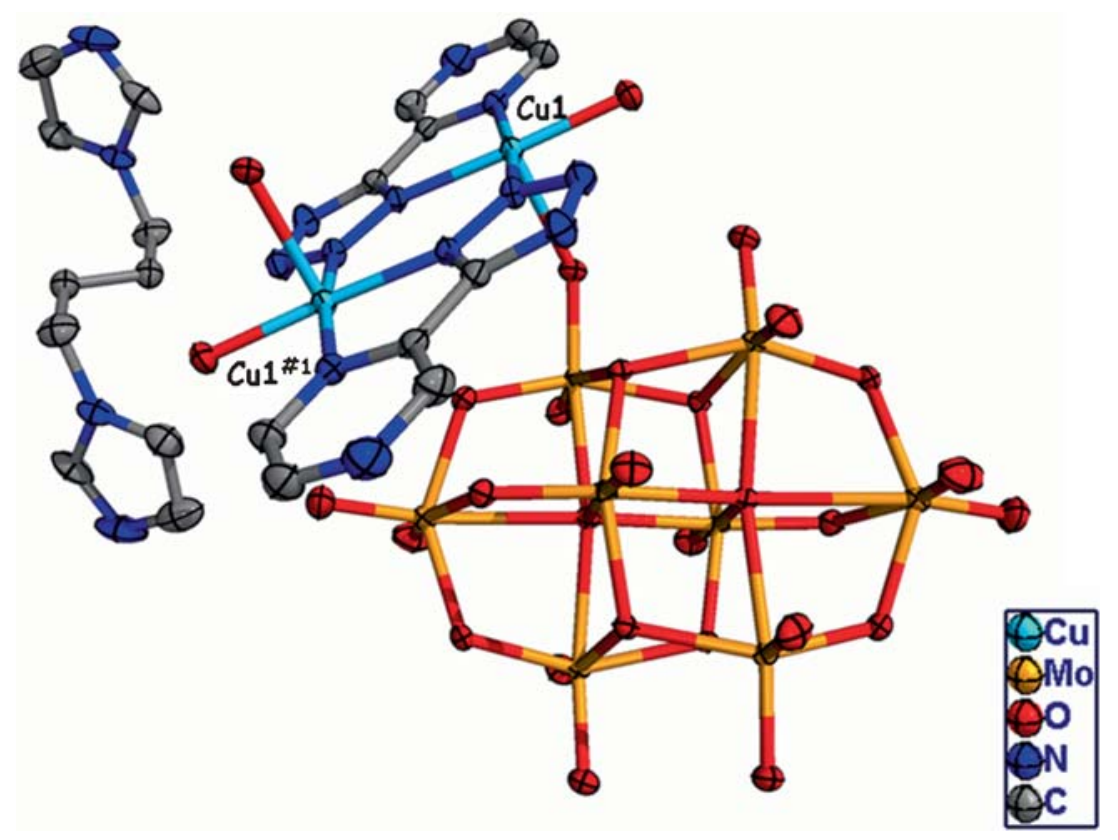

Figure 1. ORTEP drawing of $\mathbf{1}$ with displacement ellipsoids set at $50 \%$ probability. Hydrogen atoms are omitted for clarity. (Symmetry code: $\# 1,-x,-y,-z$ ). 

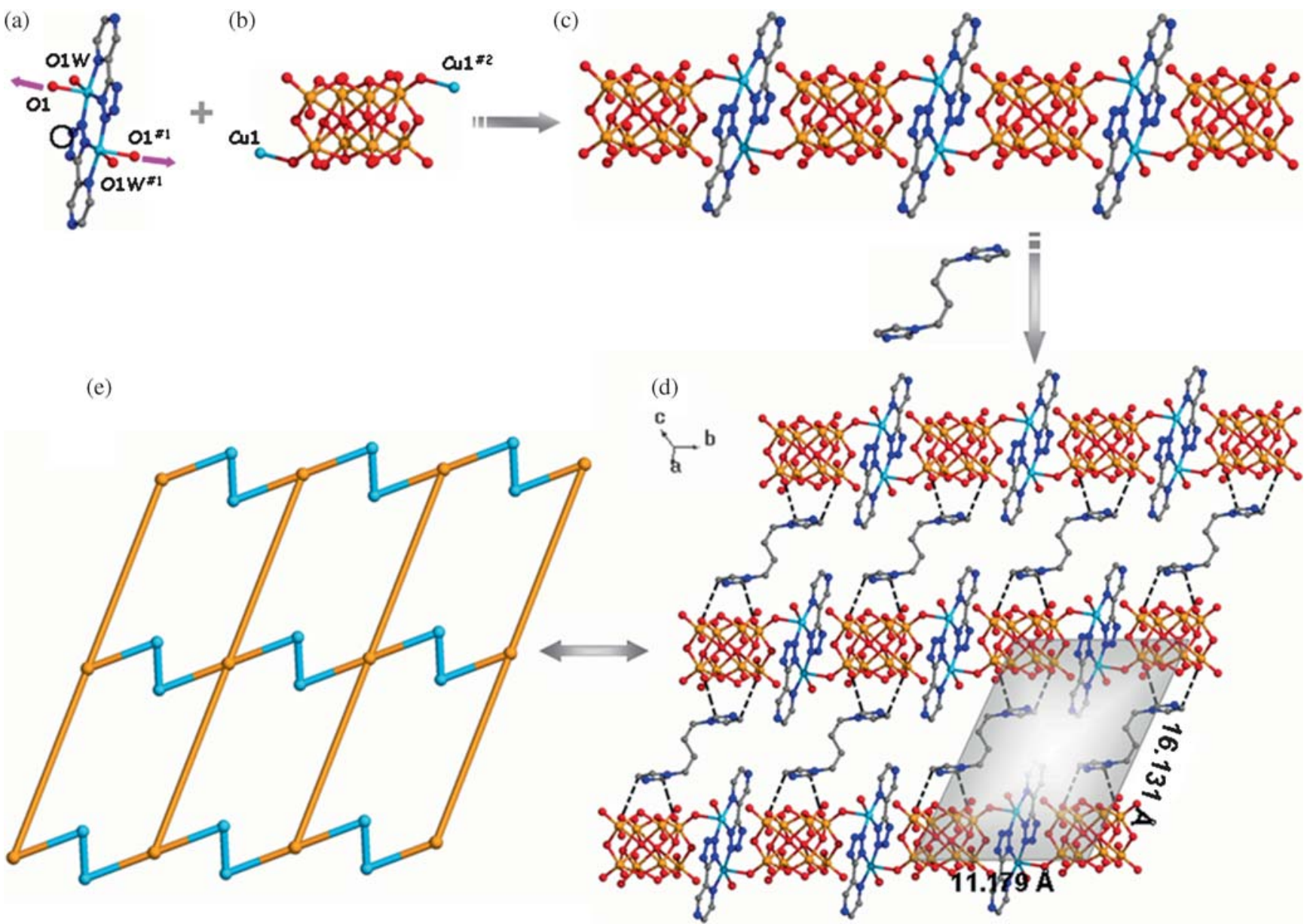

Figure 2. (a) A dinuclear $\left[\mathrm{Cu}_{2}(\text { pzta })_{2}\left(\mathrm{H}_{2} \mathrm{O}\right)_{2}\right]^{2+}$ cation; (b) a connected $\beta$-Mos cluster; (c) an inorganic-organic chain and free bbi ligands; (d) a layer formed with the cations; (e) the topology of the layer. (symmetry code: $\# 1,-x,-y,-z ; \# 2,-x, 1-x,-z$ ).

$\beta-\mathrm{Mo}_{8}$ anion is considered as a 4-connected node and each $\mathrm{Cu}$ cation as a 2-connected node, the structure of 1 is a novel $(4,2)$-connected framework with $\left(4^{4} \cdot 12^{2}\right)$ topology (figure 2e).

\subsection{IR spectrum}

The IR spectrum of compound 1 (figure S1 in Supplementary Information) exhibits characteristic peaks at 953, 881, 829 and $660 \mathrm{~cm}^{-1}$, which are attributed to $v\left(\mathrm{Mo}=\mathrm{O}_{\mathrm{t}}\right), v\left(\mathrm{Mo}-\mathrm{O}_{\mathrm{b}}-\mathrm{Mo}\right)$ and $v\left(\mathrm{Mo}-\mathrm{O}_{\mathrm{c}}-\mathrm{Mo}\right)$, respectively. ${ }^{28}$ The bands in the region of 1596 to $1101 \mathrm{~cm}^{-1}$ are ascribed to vibrations of the pzta and bbi components. The broad band at $3235 \mathrm{~cm}^{-1}$ is associated with the water molecules.

\subsection{Electrochemical properties}

POMs possess the ability of undergoing reversible multielectron redox processes, ${ }^{29}$ which make them very attractive for chemically modified electrodes to be used in electrocatalytic studies. Since the title compound is

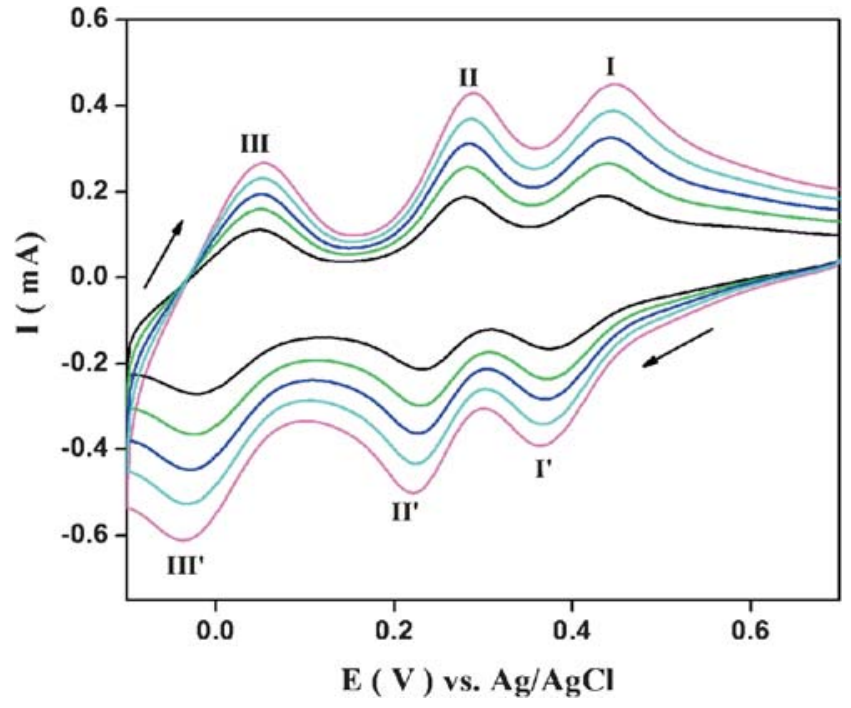

Figure 3. Cyclic voltammograms for 1-CPE in $1 \mathrm{M} \mathrm{H}_{2} \mathrm{SO}_{4}$ solution at different scan rates (from inner to outer): 50, 100, $150,200,250 \mathrm{mV} \cdot \mathrm{s}^{-1}$.

insoluble in water and common organic solvents, a bulkmodified carbon paste electrode (CPE) is the optimal choice to study its electrochemical properties. ${ }^{30}$ 

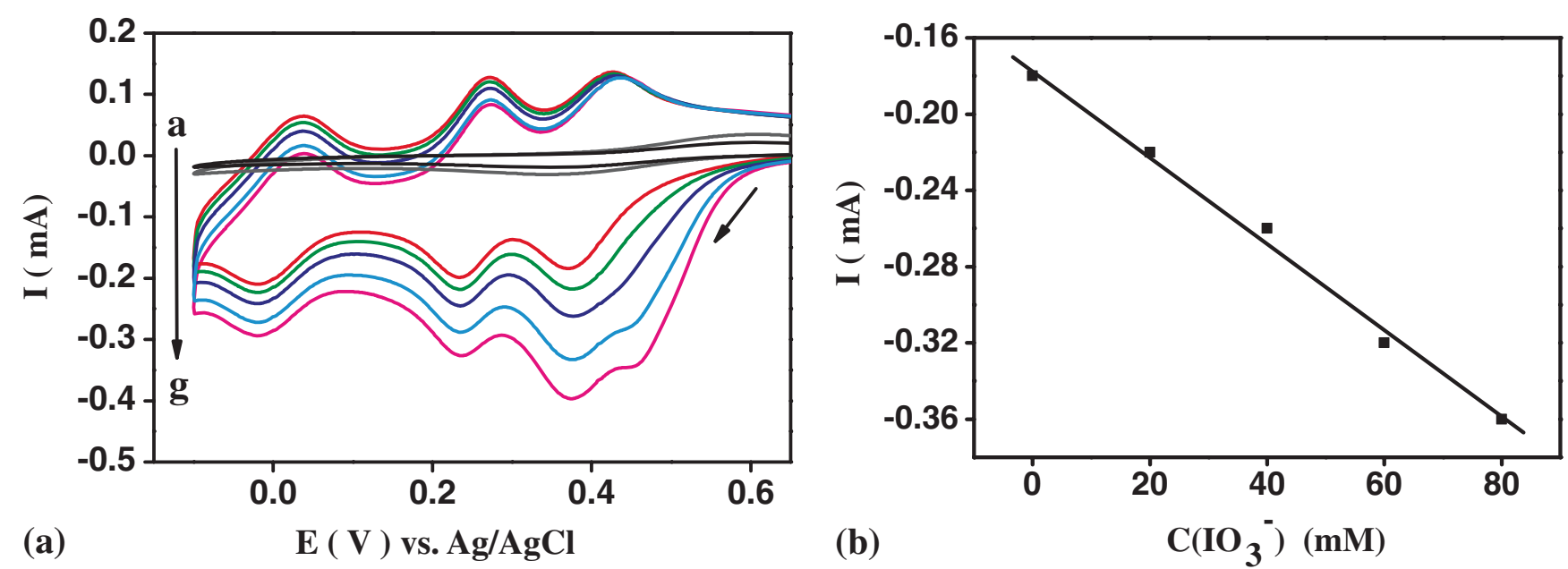

Figure 4. (A) Cyclic voltammograms: (a) bare CPE in $1 \mathrm{M} \mathrm{H}_{2} \mathrm{SO}_{4}$ solution, (b) bare CPE in $1 \mathrm{M} \mathrm{H}_{2} \mathrm{SO}_{4}$ and $\mathrm{IO}_{3}^{-}$(80 $\mathrm{mM}$ ), (c-g) 1-CPE in $1 \mathrm{M} \mathrm{H}_{2} \mathrm{SO}_{4}$ solution containing $\mathrm{IO}_{3}^{-}$(c) 0, (d) 20, (e) 40, (f) 60 and (g) $80 \mathrm{mM}$. Scan rate: $50 \mathrm{mV} \mathrm{s}^{-1}$. (B) Linear dependence of the cathodic catalytic current of wave I-I' on the $\mathrm{IO}_{3}^{-}$concentration.

The cyclic voltammograms (CV) for $\mathbf{1 - C P E}$ in $1 \mathrm{M}$ $\mathrm{H}_{2} \mathrm{SO}_{4}$ aqueous solution at different scan rates are presented in figure 3. It can be seen clearly that three reversible redox peaks (I-I', II-II' and III-III') appear in the potential range from +0.7 to $-0.1 \mathrm{~V} v s$. $\mathrm{Ag} / \mathrm{AgCl}$. The mean peak potentials $E_{1 / 2}=\left(E_{p a}+E_{p c}\right) / 2$ are $0.02 \mathrm{~V}$ (I), $0.25 \mathrm{~V}$ (II) and $0.42 \mathrm{~V}$ (III) (scan rate: 50 $\mathrm{mV} \cdot \mathrm{s}^{-1}$ ), which are all ascribed to three consecutive two-electron redox processes of Mo. ${ }^{31-33}$

POMs have been exploited extensively in electrocatalytic reactions and further with possible applications as biosensors or in fuel cells. ${ }^{34}$ Here, the reduction of iodate $\left(\mathrm{IO}_{3}^{-}\right)$was chosen as a test reaction to study the electrocatalytic activity of $\mathbf{1}$. As shown in figure $4 \mathrm{~A}$, it displays good electrocatalytic activity toward the reduction of $\mathrm{IO}_{3}^{-}$in $1 \mathrm{M} \mathrm{H}_{2} \mathrm{SO}_{4}$ solution. With the addition of $\mathrm{IO}_{3}^{-}$, the cathodic peak I' substantially increased, while the corresponding anodic peak currents decreased. Meanwhile, an extra CV peak (at $\sim 0.45 \mathrm{~V}$ ) in the $\mathrm{CV}$ of 1-CPE in the presence of iodate $(60 \mathrm{mM})$ has emerged. The reason for this appearance may be that the reduction peak I' is split. This phenomenon could be observed in the previous work. ${ }^{19,35}$ In our work, this extra peak should be identified as I". The peak potentials $E_{1 / 2}$ are $0.029 \mathrm{~V}$ (I), $0.27 \mathrm{~V}$ (II) and $0.44 \mathrm{~V}$ (III) $\left(\mathrm{IO}_{3}^{-}: 80 \mathrm{mM}\right)$, which are almost corresponding with peak potentials $E_{1 / 2}$ (without $\mathrm{IO}_{3}^{-}$). Thus, the peak potentials indicate stability in the catalytic process. ${ }^{36}$ Figure 4B shows the relationship between the first cathodic current and the concentration of $\mathrm{IO}_{3}^{-}$. The electrocatalytic efficiency of 1-CPE (based on a rough calculation using catalytic efficiency (CAT) formula $)^{37}$ towards the reduction of $\mathrm{IO}_{3}^{-}$was $c a .110 \%$ at $1 \mathrm{M} \mathrm{H}_{2} \mathrm{SO}_{4}$ containing $80 \mathrm{mM} \mathrm{IO}_{3}^{-}$, which suggests that

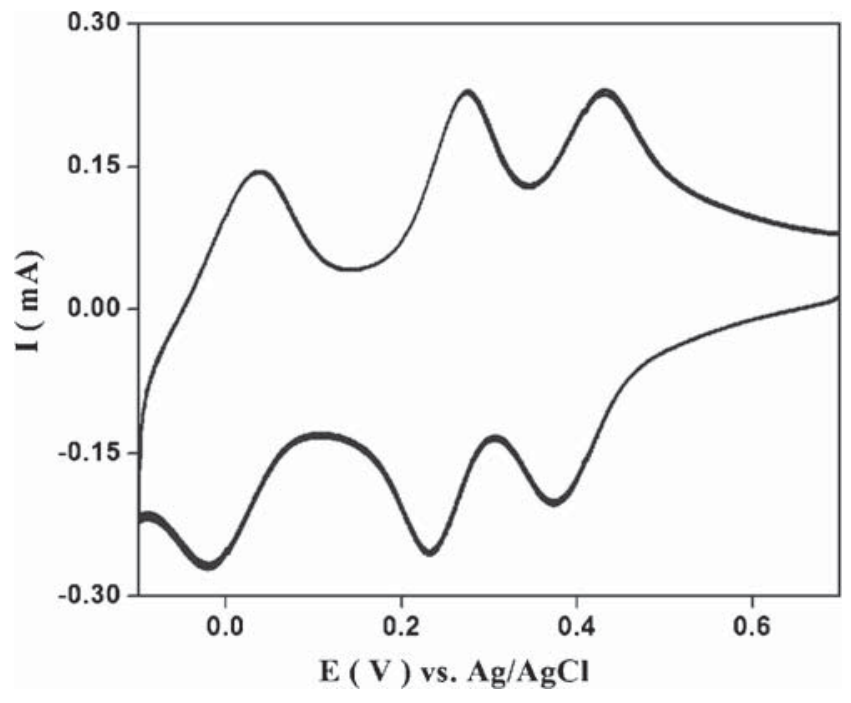

Figure 5. 40 consecutive $\mathrm{CV}$ cycles of the 1-CPE at the scan rate of $50 \mathrm{mV} \cdot \mathrm{s}^{1}$.

1 has potential usefulness for the detection of $\mathrm{IO}_{3}^{-}$. Furthermore, the stability experiment for 1-CPE has been investigated by cyclic voltammetry scanning for 40 cycles in $1 \mathrm{M} \mathrm{H}_{2} \mathrm{SO}_{4}$ solution, respectively. As shown in figure 5 , it can be seen that the electrode exhibits almost no loss in the current signal after 40 cycles, which suggests that the catalyst of 1-CPE has high stability.

\section{Conclusion}

To sum up, a new POM-based dinuclear copper (II) coordination polymer $\left(\mathrm{H}_{2}\right.$ bbi) $\left[\mathrm{Cu}_{2}(\mathrm{pzta})_{2}\left(\mathrm{H}_{2} \mathrm{O}\right)_{2}\right][\beta$ $\mathrm{Mo}_{8} \mathrm{O}_{26}$ ] (1) has been synthesized by the hydrothermal reaction. In the structure of $\mathbf{1}$, the biprotonated bbi 
ligands, acting as counter-cations, extend the structure by hydrogen bonding interactions. Furthermore, the electrochemical properties of $\mathbf{1}$ were studied, which indicate that $\mathbf{1}$ has good electrocatalytic activity towards reduction of iodate. Synthesis and property investigation on other POM-based coordination polymers constructed by dinuclear copper (II) complex are continuing in our group.

\section{Supplementary Information (SI)}

CIF file containing complete information on the structure was deposited with CCDC deposition number 992478, which is available free upon request from The Cambridge Crystallographic Data Centre via www. ccdc.cam.ac.uk/data_request/cif. The table of selected bond lengths and angles and the IR spectrum of compound $\mathbf{1}$ are given in supplementary information available at www.ias.ac.in/chemsci.

\section{Acknowledgements}

This work was financially supported by the NSF of China (21371041, 51572063), innovative research team of green chemical technology in university of Heilongjiang Province, China (2014TD007), and the science and technology innovation foundation of Harbin (2014RFXXJ076).

\section{References}

1. Coronado E and Gómez-García C J 1998 Chem. Rev. 98 273

2. Müller A and Kögerler P 2000 Coord. Chem. Rev. 199 335

3. Han Q X, He C, Zhao M, Qi B, Niu J Y and Duan C Y 2013 J. Am. Chem. Soc. 13510186

4. Yin Q S, Tan J M, Besson C, Geletii Y V, Musaev D G, Kuznetsov A E, Luo Z, Hardcastle K I and Hill C L 2010 Science $\mathbf{3 2 8} 342$

5. Hill C L 1998 Chem. Rev. 981

6. Han X B, Li Y G, Zhang Z M, Tan H Q, Lu Y and Wang E B 2015 J. Am. Chem. Soc. 1375486

7. Yaghi O M, Keeffe M O, Ockwig N W, Chae H K, Eddaoudi M and Kim J 2003 Nature 423705

8. Rowsell J L, Spencer E C, Eckert J, Howard J A and Yaghi O M 2005 Science 3091350

9. Custelcean R 2014 Chem. Soc. Rev. 431813
10. Wang S S and Yang G Y 2015 Chem. Rev. 1154892

11. Vaddypally S and Samar K D 2005 Inorg. Chem. 44 8846

12. Monima S, Tanmay C and Samar K D 2011 Dalton Trans. 402954

13. Du D Y, Yan L K, Su Z M, Li S L, Lan Y Q and Wang E B 2013 Coord. Chem. Rev. 257702

14. Reinoso S, Vitoria P, Lezama L, Luque A and GutiérrezZorrilla J M 2003 Inorg. Chem. 423709

15. Reinoso S, Vitoria P, Gutiérrez-Zorrilla J M, Lezama L S, Felices L and Beitia J I 2005 Inorg. Chem. 449731

16. Cao R G, Liu S X, Xie L H, Pan Y B, Cao J F, Ren Y H and Xu L 2007 Inorg. Chem. 463541

17. Yu F, Kong X J, Zheng Y Y, Ren Y P, Long L S, Huang R B and Zheng L S 2009 Dalton Trans. 9503

18. Han Q X, Ma P T, Zhao J W, Wang J P and Niu J Y 2011 Inorg. Chem. Commun. 14767

19. Li S B, Ma H Y, Pang H J, Zhang Z F, Yu Y, Liu H and Yu T T 2014 Cryst. Eng. Comm. 162045

20. Li S B, Ma H Y, Pang H J, Li Z and Zhang Z F 2014 Inorg. Chem. Commun. 4415

21. Sheldrick GM (2000) shelxtl (version 6.1) (Bruker Analytical, X-ray Instruments Inc. : Madison, Wisconsin)

22. Li S L, Lan Y Q, Ma J F, Yang J, Wang X H and Su Z M 2007 Inorg. Chem. 468283

23. Allis D G, Burkholder E and Zubieta J 2004 Polyhedron 231145

24. Wu H, Yang J, Liu Y Y and Ma J F 2012 Cryst. Growth Des. 122272

25. Lan Y Q, Li S L, Wang X L, Shao K Z, Su Z M and Wang E B 2008 Inorg. Chem. 47529

26. Brown I D and Altermatt D 1985 Acta Crystallogr. B 41 244

27. Sha J Q, Peng J, Zhang Y, Pang H J, Tian A X, Zhang P P and Liu H 2009 Cryst. Growth Des. 91708

28. Klemperer W G and Shum W 1976 J. Am. Chem. Soc. 988291

29. Xi X D, Wang G, Liu B F and Dong S J 1995 Electrochim. Acta 401025

30. Han Z G, Zhao Y L, Peng J, Feng Y H, Yin J N and Liu Q 2005 Electroanalysis 171097

31. Dong S J and Wang B X 1992 Electrochim. Acta 3711

32. Dai L M, You W S, Wang E B, Wu S X, Su Z M, Du Q H, Zhao Y and Fang Y 2009 Cryst. Growth Des. 92110

33. Sha J Q, Liang L Y, Sun J W, Tian A X, Yan P F, Li G M and Wang C 2012 Cryst. Growth Des. 12894

34. Keita B, Oliveira P D, Nadjo L and Kortz U 2007 Chem. Eur. J. 135480

35. Qu Z K, Yu K, Zhao Z F, Su Z H, Sha J Q, Wang C M and Zhou B B 2014 Dalton Trans. 436744

36. Qin Q S, Du D Y, Guan W, Bo X J, Li Y F, Guo L P, Su Z M, Wang Y Y, Lan Y Q and Zhou H C 2015 J. Am. Chem. Soc. 1377169

37. Keita B, Belhouari A, Nadjo L and Contant R 1995 J. Electroanal. Chem. 381243 